\title{
Underbanked and Foreign Reserve Deficient: Is Cryptocurrency the Strategic Panacea for Small South Pacific Nations?
}

\author{
Charles A. Rarick \\ Purdue University Northwest \\ Casimir C. Barczyk \\ Purdue University Northwest \\ Arifin Angriawan \\ Purdue University Northwest
}

\begin{abstract}
A number of small South Pacific nations suffer from a lack of robust international banking relationships and a shortage of foreign reserves. The Republic of the Marshall Islands decided a solution to these problems was to create a sovereign cryptocurrency for the country. Other small nations in the region are attempting to follow the Marshall Islands and create their own cryptocurrencies. This case explores the opportunities and threats of such a bold financial experiment and raises questions concerning the future of sovereign cryptocurrency in the region and beyond.
\end{abstract}

Keywords: Cryptocurrency, Bitcoin, Marshall Islands, Papua New Guinea, Foreign Reserves, Unbanked

\section{INTRODUCTION}

The lack of a strong presence of international banking and their correspondent relationships, as well as a persistent shortage of foreign reserves, are two issues facing a number of smaller South Pacific nations. With increased regulation and oversight of international banking, mainly done by the United States, many of these countries are becoming underbanked and risk becoming unbanked. The expense of meeting international banking rules and regulations is causing financial institutions to reconsider a presence in nations with small populations, and international correspondent banking arrangements are becoming scarce in these countries. In addition, some of the countries have experienced shortages in foreign reserves, making international transactions difficult.

A possible solution to these financial difficulties could be the adoption of cryptocurrency as legal tender. A cryptocurrency is a form of monetary exchange that uses cryptography to secure virtual transactions in a safe way. Currently there are more than 700 cryptocurrencies in existence, the first and most popular one being Bitcoin. Cryptography helps curb the creation of additional units of a cryptocurrency, thus preventing counterfeiting. This helps make the cryptocurrency fraud-proof. Using a public ledger to store a cryptocurrency's virtual buy and sell transactions, with the identity of coin owners 
encrypted, ensures the legitimacy of the record keeping. All transactions in the ledger are checked to make sure that the coins used are owned by the spender involved in the transaction - much like a credit card is verified by the bank that issues a customer's card. This prevents identity theft. The ledger is referred to as a transaction blockchain, which uses technology to secure digital transactions through encryption and "smart contracts" so as to make the process virtually unhackable.

In 2008, a mysterious programmer going by the name of Satoshi Nakamoto published a paper, which led to the creation of Bitcoin in 2009 through open source software. Bitcoin, which uses a peer-to-peer network and blockchain technology, was declared the world's first successful cryptocurrency to be issued. Cryptocurrency is not controlled by any governmental agency, has no central clearing house, and is not pegged to any "real" currency of the world. There are several exchanges where cryptocurrencies can be bought and sold, as well as ATMs where one can receive the currency. Bitcoins have been "mined" by solving increasingly complex mathematical problems. The popularity of Bitcoins caused other cryptocurrencies to be created such as Litecoin, Ethereum, and many more. Cryptocurrencies can be used to purchase some goods and services and to make financial transfers to others. It is believed that the first Bitcoin purchase was made by a computer programmer in Florida who was looking to buy a pizza. Laszlo Hanyecz offered 10,000 Bitcoins on a Bitcoin forum to anyone who would buy him a pizza. Another forum member called a Jacksonville, Florida Papa John's, ordered two pepperoni pizzas and had them delivered. When Hanyecz paid the 10,000 Bitcoins, he and Papa John's made history.

While widespread usage of Bitcoins for consumer purchases has not yet occurred, Bitcoins and other cryptocurrencies have taken on a new importance in terms of potential national currency replacements. Issues of fraud, money laundering, funding for terrorists, and illegal transactions being conducted with cryptocurrency has made the new form of money a concern to some governments. The reason is that cryptocurrencies are independent from formal banking systems and government regulations, thereby making tax evasion simpler for people who use them. Taxable income is based on what a person reports to a country's revenue service. As such, one can under-report income because transactions using cryptocurrency are made technologically complex, tough to track, and extremely difficult to account for. The blockchain systems of anonymity that cryptocurrencies such as Bitcoin offer provide a simple means to launder money. Instead of using an intricate array of financial actors and offshore bank accounts, money can be easily laundered through cryptocurrencies that use digital wallets, which provide anonymity for the parties involved in the transaction.

Advocates of cryptocurrency see it as a means to raise capital and to provide citizens with an easy, inexpensive way to transfer funds domestically and internationally. Cryptocurrency can also provide additional foreign reserves because more nations are adopting it as a form of payment. While Bitcoin was created as a decentralized form of currency not tied to a specific country or central bank, it now has five million active users, $51 \%$ of which are outside the U.S. By 2030, it is expected to be the sixth largest revenue currency in the world. As more nations adopt blockchain technology, Bitcoin is positioned to become the next global form of currency and one of the few not connected to a nation's economy or banking system. Countries will begin adding it to their purses of foreign reserves.

\section{THE MARSHALL ISLANDS}

The Republic of the Marshall Islands wants to create the world's first cryptocurrency legal tender. Currency use in the South Pacific varies (Figure 1). The Marshall Islands currently uses the U.S. dollar as its legal tender. However, it has made plans to issue the sovereign (SOV) as its legal tender because of an increasing lack of international banking in the country. This cryptocurrency would operate alongside the U.S. dollar. The Marshall Islands (site of many U.S. nuclear weapons tests in the past) relies on the United States for economic aid. The country gained its independence from the United States in 1986 yet receives U.S. economic aid and is home to a U.S. military garrison used as part of a strategic missile defense network. Many locals work for the garrison and have a need to have their paychecks cashed. Currently only one international bank operates in the country and it has plans to leave. First Hawaiian Bank provides the correspondent banking relationship the Marshall Islands needs to be linked to the 
international banking system. Without First Hawaiian Bank the country would be cut off from the network that provides international banking services. A digital sovereign currency would seem to solve this problem in that funds can be transferred over the Internet and do not require a banking relationship.

\section{FIGURE 1 \\ SOUTH PACIFIC AND CURRENCY USE}

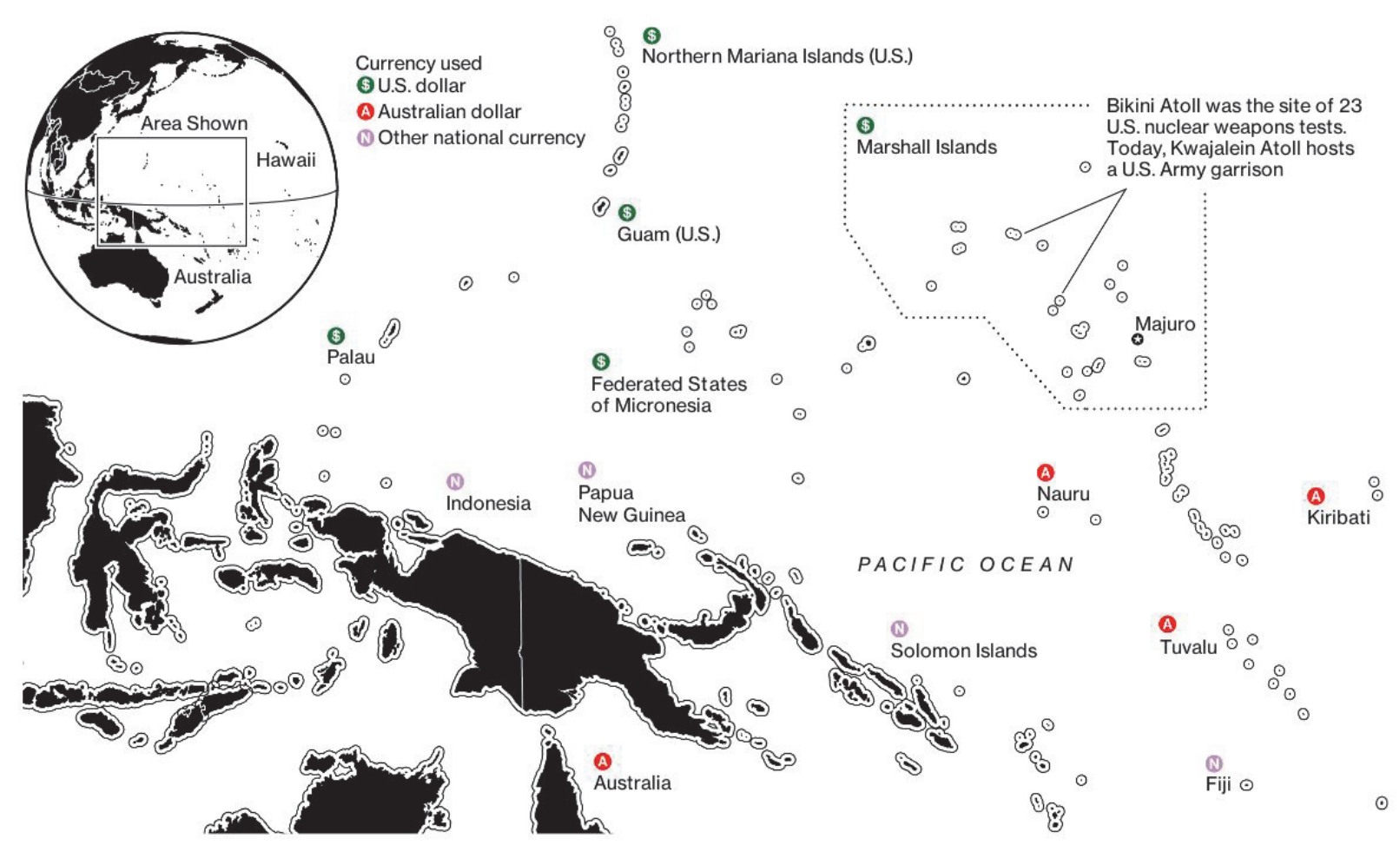

Source: Bloomberg Businessweek. December 17, 2018.

On February 26, 2018 the Marshall Islands enacted the Sovereign Currency Act, which introduced the SOV as legal tender in the country. Both the United States and the International Monetary Fund (IMF) warned against such a move suggesting that the plan could increase financial instability, promote money laundering, and provide funding for terrorism. The IMF warned that the new currency might provide fewer benefits and greater costs than expected. The Marshall Islands has countered that SOV transactions would be monitored and identities verified reducing the risks that the country would become a haven for money laundering and terrorist funding. With few opportunities for foreign currency other than the U.S. government payments and the sale of fishing rights in the country's waters, the Marshall Islands sees the SOV as its only solution. The Marshall Islands plans to issue 24 million SOVs, half of which would be sold at an anticipated price of $\$ 50$ each and the remaining half distributed to citizens over a five year period.

Use of a digital currency would require a more reliable Internet infrastructure than currently found in the Marshall Islands. There is also the issue of the volatility of current cryptocurrencies and how this might affect the financial system. Bitcoins, for example, have experienced very significant volatility since their introduction, ranging in value from less than $\$ 0.01$ to just shy of $\$ 20,000$ (Figure 2). The absence of a central bank with discretionary powers over cryptocurrencies means that purchasing power stability is not really possible. A cryptocurrency could be less volatile and more stable only if it is the only form of money used globally and there is no exchange of it with other currencies. 
FIGURE 2

\section{BITCOIN PRICE HISTORY}

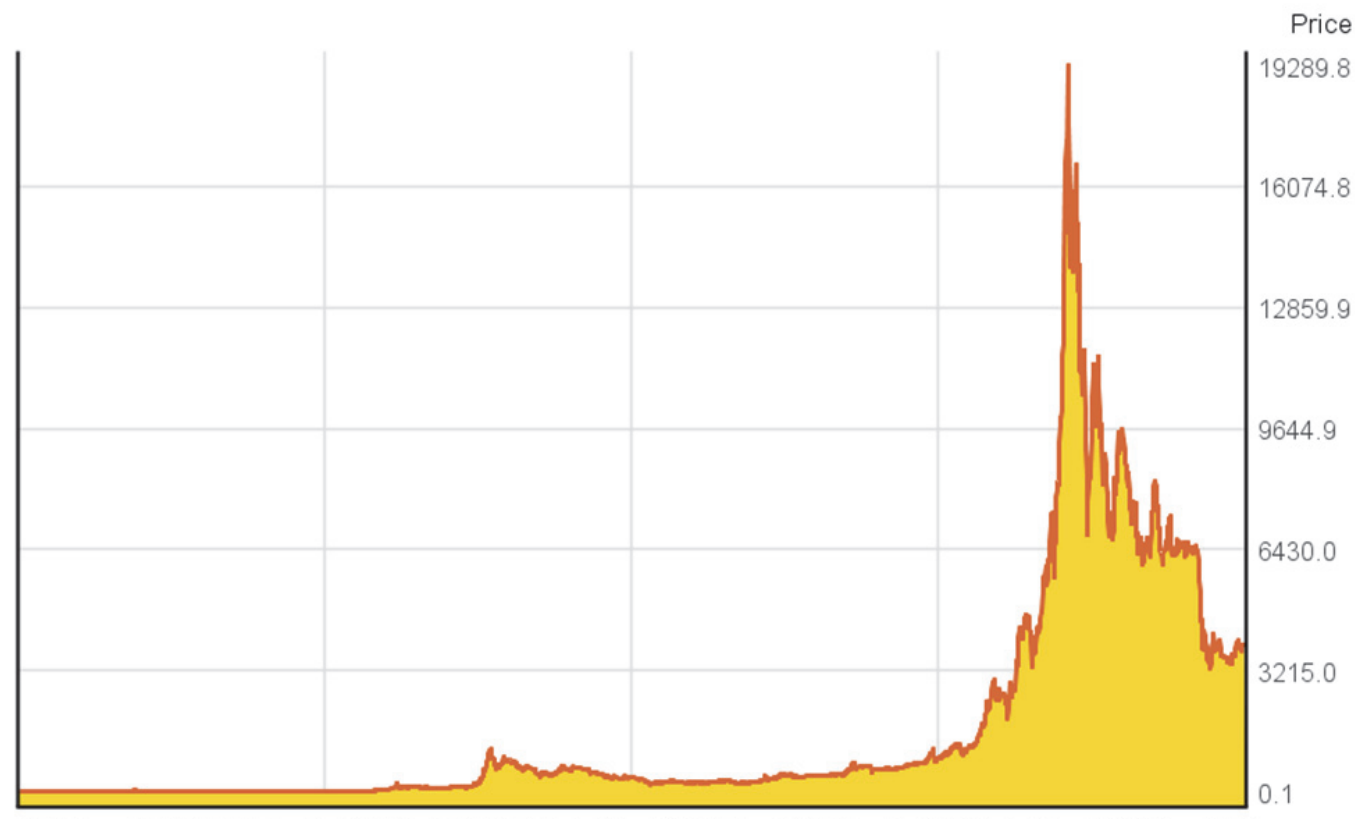

2010 Aug 20112012 Jun Oct 2013 Jul Oct 2014 Jul Nov 2015 Sep 2016 Jun Oct 2017 Jul Nov 2018 Sep 2019

Source: 5yearcharts.com

\section{PAPUA NEW GUINEA}

While the Marshall Islands started the rush towards sovereign cryptocurrency, other small nations in the South Pacific are taking note and making plans, or considering a similar move. Papua New Guinea (PNG) has proposed the creation of the Torokina as a sovereign cryptocurrency using a Special Economic Zone (SEZ). Currently Papua New Guinea uses the kina as its legal tender, but much of the population is unbanked. According to the Bank of PNG, $85 \%$ of the local people with low incomes reside in rural areas without access to formal financial services. This lack of access to financial resources is what Ledger Atlas hopes to address by establishing the SEZ. Ledger wants to focus on creating opportunities designed to solve problems such as financial inclusion. Jack Saba, co-founder of Ledger Atlas, says that the special economic zone will create a free market that pushes all participants to provide the best blockchain-based services possible. Over time, the company hopes to grow the SEZ using blockchain technology into a stable economic ecosystem. This is a difficult idea for the people of Papua New Guinea because their culture is short-term oriented. They focus on the past and present with a strong respect for tradition. They have little perspective for the long run because of their unpredictable and difficult environment. As such, the long term is "just around the corner."

The PNG locals have resisted the establishment of an SEZ that was proposed in a Memorandum of Understanding signed by Ledger Atlas and Prime Minister Peter O’Neill in April 2018. Working with several Members of Parliament, the locals advanced a petition claiming that the Memorandum of Understanding being pushed through as a legal document did not follow democratic process and seemed like a one-sided decision made by the government. The Memorandum bill was signed without any consultation with locals, landowners, concerned government agencies or immigration authorities. Local people objected to substantive provisions in the bill that granted the proposed SEZ, to be operated by Ledger Atlas, the right to govern and manage itself. It could issue passports, enact its own laws, prosecute 
offenders, levy taxes, create fees, and impose fines. The SEZ would have extraterritoriality status, have its own courts, and exempt itself from Papua New Guinea's laws.

The proposal to create the SEZ in Papua New Guinea is a response to other underlying financial problems. For example, when people from PNG take 1000 kina overseas, they usually get \$250 USD. Effectively people lose $75 \%$ of the value of their kina as soon as they take their currency beyond the island's shores. Another problem is that foreign reserves in Papua New Guinea have been running low in recent years. The country relies heavily on natural resources for foreign exchange and the main export, natural gas, has recently experienced a drop in price. The drop in foreign reserves has forced the country to restrict imports of non-essential items. When foreign reserves get low a country has difficulty financing international trade which is harmful to the country's economy. Businesses must wait until they receive hard currency to make international purchases. The creation of money (Torokina) through the SEZ could potentially create additional reserves for Papua New Guinea.

While Papua New Guinea is rich in resources and could potentially resolve its foreign reserve shortages, political issues have reduced that potential. One of PNG's islands, Bougainville, is the site of one of the world's largest copper mines. Bougainville also has significant gold reserves. The copper mine, Panguna, is believed to hold the world's largest untapped deposits of copper. Unfortunately, a civil war developed over the mine as residents of Bougainville were concerned about pollution, revenue sharing, and land rights. When the war finally ended an estimated 20,000 people had been killed. Bougainville gained some autonomy but the mine was closed and has remained closed resulting in a loss of foreign income. Bougainville is pushing for complete independence and the Chinese are interested in gaining access to the mine. Papua New Guinea has close ties with Australia and the United States. The government in Port Moresby, the capital of Papua New Guinea, is not likely to grant independence to Bougainville. Complete independence for Bougainville would most likely increase Chinese investment on the island but no additional foreign income for Papua New Guinea. Australia and the United States have concerns over the growing influence of China in the region.

Prime Minister O'Neill was a supporter of the creation of the Torokina as a new legal tender for Papua New Guinea. However, due to political turmoil he resigned as Prime Minister in May, 2019. The Torokina, if still politically viable, would be pegged to the price of gold since the country currently has over $\$ 2$ billion in gold extraction a year. It accounts for $0.7 \%$ of the world's supply. As such, gold would seem like a reasonable way to support the new cryptocurrency. Pegging it to gold would have the potential to reduce the price volatility seen in other cryptocurrencies. The aim of the Torokina would be to combine natural resources with blockchain technology to create a gold backed cryptocurrency that performs on par with major currencies like the US dollar, Japanese yen, or British pound sterling in trade and commerce.

\section{THE FUTURE OF SOVEREIGN CRYPTOCURRENCY}

The interest in cryptocurrency extends beyond the South Pacific. The government of Japan is aiming for a large share of consumer payments to be made digitally. Surprisingly the technologically sophisticated Japanese currently make many payments with banknotes and coins. With the Olympics headed to Japan, the country wants a better payment system. The Mitsubishi Financial Group, Japan's largest bank, has partnered with an American firm to offer its own digital currency. If the world's third largest economy creates a common digital currency it may lend support to the idea being proposed in the South Pacific. While digital sovereign currency may come to the Marshall Islands, Papua New Guinea, and other countries, questions remain. Are there really any significant differences between creating a cryptocurrency such as the SOV and the fiat currency of other nations including the U.S. dollar? Would

countries benefit from backing the digital currency with an asset such as gold as in the case of Papua New Guinea? Are there alternatives to the creation of sovereign cryptocurrency as a solution to the financial problems faced by certain nations in the world? Weighing the potential benefits and costs, is this the right move for these countries? 


\section{REFERENCES}

Ammous, S. (2016). Can cryptocurrencies fulfil the functions of money? Working Paper No. 92, Columbia University, Center on Capitalism and Society. Retrieved from https://papers.ssrn.com/sol3/papers.cfm?abstract_id=2832769.

Anderson, T. (2014). Bitcoin - Is it just a fad? History, current status and future of the cyber-currency revolution. Journal of International Banking Law and Regulation, 7, 373-380.

Clark, A., \& Murtaugh, D. (2019, February 12). The remote island sitting on $\$ 58$ billion of gold and copper. Retrieved from https://www.bloomberg.com/news/articles/2019-02-11/-58-billionpacific-mine-claim-seen-at-risk-as-referendum-nears.

Faber, E. (2017, October 31). Trade finance: A catalyst for foreign currency growth in PNG. Asian Development Blog. Retrieved from https://blogs.adb.org/blog/trade-finance-catalyst-foreigncurrency-growth-png.

Griswold, A. (2014, May 23). The first ever Bitcoin purchase was remarkably inglorious. Slate. Retrieved from https://slate.com/business/2014/05/first-bitcoin-purchase-two-pepperoni-pizzas-from-papajohn-s.html.

Halpin, J. (2018, August 10). Torokina: A cryptocurrency with a dream to rescue Papua New Guinea. Asian Pacific Report. Retrieved from https://www.5yearcharts.com/bitcoin-price-history-chartsand-milestones/

IMF Country Report. (2018, September). Republic of the Marshall Islands Report No. 18/270.

Kavanamur, D. (2001). The interplay between politics and business in Papua New Guinea. Technical Working Paper, Australian National University. Retrieved from http://hdl.handle.net/1885/141960.

Light, J. (2018, December 17). The country that bet on crypto. Bloomberg Businessweek, 59-63.

Matsumoto, F. (2018, December 11). A small island gets caught in China's Pacific power game with West. Nikkei Asian Review.

Nyango, K. (2018, October 26). The proposed special economic plan in PNG gets a refusal from the locals. Tech in Pacific. Retrieved from http://www.techinpacific.com/proposed-specialeconomic-plan-png-gets-refusal-locals/.

Orcutt, M. (2019, January 22). Will people ditch cash for cryptocurrency? Japan is about to find out. MIT Technology Review.

Reese, A. (2018, May 19). US blockchain startup to operate special economic zone in Papua New Guinea. ETHNews.

Staff reporter. (2018). Government to cede sovereignty in cryptocurrency gamble. The Tokaut Blog. Retrieved from http://pngicentral.org/reports/govt-to-cede-sovereignty-in-cryptocurrency-gamble.

Wernau, J. (2018, June 23). When a country gets unbanked - Complex bank rules leave tiny Marshall Islands further stranded. Wall Street Journal Eastern Edition. 